\title{
Morir en la capital
}

Ha sido una aspiración de largo aliento revertir el centralismo universitario que ha preponderado en nuestro país. Las primeras experiencias descentralizadoras en Medicina surgen en la década de 1980 en Salto y Paysandú en los ciclos clínicos, con una impronta marcada por el compromiso de docentes locales, convencidos de esta necesidad. No obstante, el número promedio de estudiantes no superó los 50 por año en la Región Norte hasta 2019. Pasaron 30 años para que esta situación comenzara a cambiar, no exenta de desafíos.

"Cuando quieras estudiar, morís en la capital" (1)

La apuesta de la Universidad de la República a la radicación y desarrollo de núcleos académicos de las ciencias biológicas de alto nivel en el interior a partir del año 2010, fue creando las condiciones para sustentar los primeros años no clínicos de la carrera. La puesta en marcha del Ciclo inicial optativo del Área Salud en Paysandú en 2014, habilitó una puerta de entrada amplia a las diversas orientaciones profesionales, incluida Medicina. En el año 2015 se crea un grupo de trabajo integrado por docentes regionales para el estudio de la factibilidad de la implementación de la carrera en la Región Norte, y el CENUR Litoral Norte destina dineros para la creación de los cargos necesarios. La propuesta final se presenta y aprueba en noviembre de 2019 en el Consejo de Facultad de Medicina y en el Consejo Directivo Central $^{(2)}$

"Si te tienen que operar, morís en la capital" (1).

El 66,8\% de los médicos del país trabaja en Montevideo y únicamente el 8\% está radicado al norte del río Negro $^{(3)}$. Esta desigual distribución de recursos humanos se traduce en faltantes críticos en algunas especialidades, generando una brecha de accesibilidad entre el interior y la capital.

"Y ruegan a los muchachos no se vayan por favor" "(1).

El estudiante de Medicina que migra a la capital a estudiar difícilmente regresa a su lugar de origen. El desarraigo es inevitable, es emocional y en tres tiempos: cuando parte de su lugar, cuando se plantea regresar y la revivenciación de la experiencia si luego parten sus hijos ${ }^{(4)}$. Al costo emocional se le suma el costo económico del desarraigo, que marca una desigualdad entre quienes pueden y quienes no pueden costearlo.

"La capital nos ofrece buenos libros al leer",(1).

En Montevideo radica el 100\% de las ofertas de formación en posgraduación. Esto no sucede en el interior, lo que dificulta la especialización "in situ" de los graduados. Pero, además, esto se acompaña de un imaginario colectivo vinculado a que el profesional del interior está desactualizado, dado que los servicios de referencia académica están concentrados en la capital ${ }^{(4)}$.

"Y que puedas progresar, no solo en la capital"(1).

Los cursos en este 2020 mostraron un incremento significativo de la matrícula. Actualmente, 179 estudiantes están cursando Medicina en el CENUR Litoral Norte, y se prevé un incremento exponencial para 2021. Pero este número no es producto de una disminución de la matrícula en Montevideo, si bien se ha dado un fenómeno de traslado por goteo de estudiantes al CENUR. Este fenómeno responde a una mayor accesibilidad de la población del interior a la educación terciaria, derecho fundamental que se ve cristalizado en este proceso. La apuesta es fortalecerlo para generar profesionales instalados, sensibles con los problemas de salud de las comunidades que los vieron crecer, estudiar, trabajar; comunidades que han acompañado su formación y a las que devolverán su conocimiento. Para que, parafraseando a Pablo Estramín, el futuro no siga siendo "morir en la capital"(1).

Diana Domenech Carboni Coordinadora de la carrera de Medicina - Paysandú. Facultad de Medicina, UdelaR Prof. Agda. del Dpto. Medicina Familiar y Comunitaria. Facultad de Medicina, UDdelaR Magister en Psicología Clínica Familiar Sistémica

\section{Bibliografía}

1. Estramín P. Morir en la capital [Video]. Álbum: Lo mejor del folklore uruguayo. Montevideo: 1992. Disponible en: https://www.youtube.com/watch?v=h7OPyEvTnXo [Consulta: 5 noviembre 2020].

2. Universidad de la República. Consejo Directivo Central. Resolución n51. Sesión ordinaria del 19/11/2019. 
3. González Mora F, Barbero Portela M, Barrero Salgado G; Batthyany K (coord.). La profesión médica en Uruguay. Caracterización del perfil profesional y la inserción laboral de los médicos en Uruguay. Montevideo: Colegio Médico del Uruguay, 2018.

4. Levin R, Toledo A, Romero M. Investigación cualitativa sobre facilitadores y obstáculos socio culturales para la radicación de los profesionales médicos en el interior del país. Montevideo: Unidad de Sociología de la Salud, 2012. (Financiado por ANII a través del Fondo Sectorial de Salud). 